\title{
A GÊNESE DA INTUIÇÃO DO OUTRO E A FORMAÇÃO DA COMUNIDADE TRANSCENDENTAL: A QUESTÃO DA INTERSUBJETIVIDADE EM HUSSERL
}

\author{
[THE GENESIS OF THE INTUITION OF THE OTHERNESS AND THE FORMATION OF THE \\ TRANSCENDENTAL COMMUNITY: THE QUESTION OF INTERSUBJECTIVITY IN HUSSERL]
}

\section{Marcos Alexandre Alves * Centro Universitário Franciscano, Brasil}

\begin{abstract}
Resumo: Este artigo objetiva examinar a gênese da intuição do outro e como ocorre a formação da comunidade transcendental, ou seja, investigar a questão da intersubjetividade em Husserl. A fenomenologia evoca a primazia do estudo eidético, tomando as essências no mais alto nível de pureza intencional. No sistema redutivo fenomenológico, o ego pode se autoexplicar de maneira rigorosa e revelar a si mesmo sua estrutura de possibilidade do conhecimento. Mostra-se que, Husserl, para não se cair no solipsismo, adota uma nova perspectiva de abordagem do sistema redutivo (epoché abstrativa), que proporciona identificar as estruturas transcendentais das relações com os outros sujeitos. Evidencia-se que, ao intencionar $\mathrm{o}$ outro, na perspectiva transcendental, o eu se depara com uma estrutura pura de vinculação, que lhe permite a constituição de um mundo comum, ou seja, o sentido da coletividade. Portanto, a fenomenologia, proporciona, agora desde novas bases, a constituição do eu transcendental e sua realidade concreta, como mônada, e ao descrever a questão da intersubjetividade, enquanto comunidade dos sujeitos, como fundamento da transcendência, emancipa-se do solipsismo e completa o sistema redutivo.
\end{abstract}

Palavras-ChaVe: Fenomenologia; Eu; Outro; Solipsismo; Intersubjetividade
ABSTRACT: This article aims to examine the genesis of the intuition of the other and how the formation of the transcendental community occurs, that is, to investigate the issue of intersubjectivity in Husserl. Phenomenology evokes the primacy of eidetic study, taking essences to the highest level of purity intentionally. In the phenomenological reductive system, the ego can rigorously explain itself and reveal to itself its structure of the possibility of knowledge. It is shown that, Husserl, in order not to fall into solipsism, adopts a new perspective of approach to the reductive system (abstract epoché), which allows identifying the transcendental structures of the relations with other subjects. It is evident that, when intending the other, in the transcendental perspective, the self is faced with a pure structure of connection, which allows it to constitute a common world, that is, the sense of collectivity. Therefore, phenomenology, now provides, from new bases, the constitution of the transcendental self and its concrete reality, as a monad, and when describing the issue of intersubjectivity, as a community of subjects, as the foundation of transcendence, it emancipates itself from solipsism and complete the reductive system. KEYwORDS: Phenomenology; Self; Other; Solipsism; Intersubjectivity

* Doutor em Educação pelo Programa de Pós-Graduação em Educação da Universidade Federal de Pelotas - PPGE/UFPel. Professor do Curso de Filosofia e do Mestrado em Ensino de Humanidades e Linguagens - Centro Universitário Franciscano - UNIFRA. E-mail: maralexalves@gmail.com 


\section{INTRODUÇÃO}

Wa região transcendental, a possibilidade da evidência do ego transcendental tem

1 sua origem na afirmação cartesiana "eu sou" legitimada pelas reduções fenomenológicas. No entanto, as análises transcendentais de Husserl ampliam as

12 constatações cartesianas sobre o ego, pois defendem que a evidência "eu sou" implica uma estrutura apriorística da consciência que possibilita ao ego a apercepção de si mesmo e de seu fluxo de pensamentos. Nessa estrutura pura, o ego se apresenta como ser individual e concreto, e polo de seus estados vividos, o que lhe confere a possibilidade tanto de experiências internas quanto externas, passíveis de predicação rigorosa (HUSSERL, 2001).

O objetivo da fenomenologia, no campo transcendental, é voltar o olhar para o ego reduzido, como espectador desinteressado, e permitir que ele se apresente a fim de descrever seus modos próprios constituintes e como o ego compõe seu fluxo de vividos intencionais na subjetividade transcendental, região onde todo e qualquer vivido recebe seu sentido. Dessa maneira, a fenomenologia passa a se apresentar como uma egologia pura, ou seja, ciência do ego reduzido (transcendental) ${ }^{1}$.

Husserl, ao apresentar a evidência do campo transcendental do eu reduzido e sua vida interna pura, entende que a fenomenologia revela toda uma estrutura apriorística do ego que se estabelece como fundamento de suas cogitaciones. Isso significa que o ego é o critério absoluto de toda verdade e constituição do mundo vivido. Porém, sugem algumas questões: A fenomenologia de Husserl é fundamentada num solipsismo? Como o ego intenciona os outros seres humanos? Qual é a gênese da constituição transcendental do outro? O sistema redutivo insere a fenomenologia em uma região nova de investigação destituída dos conteúdos empíricos do mundo e apresentada como conjunto dos fenômenos ideais constituídos pela consciência pura. Resta averiguar como o sujeito identifica o outro no âmbito transcendental.

\section{O EGO NA ESFERA TRANSCENDENTAL E COMO POLO DOS VIVIDOS}

Ao reduzir a consciência ao seu nível de pureza se identifica que a estrutura tipo das atividades cognitivas, cogito-cogitatum, torna evidente uma subjetividade também pura, de estruturas e modos a priori. Isso resulta na constatação de que "o ego transcendental (e, se considerarmos sua réplica psicológica, a alma) é aquilo que ele é unicamente em relação aos objetos intencionais" (HUSSERL, 2001, p. 81). Nesses parâmetros, através da reflexão transcendental o ego pode compreender e descrever-se a si mesmo fenomenologicamente.

O sistema redutivo de Husserl possibilita compreender que o ego transcendental se revela a partir de seus atos cognitivos puros, ou seja, da relação cogito-cogitatum reduzidos às suas estruturas a priori. A elucidação do processo de síntese, no qual os objetos são compreendidos como polos das atividades da consciência e que, por esse processo se pode identificar o objeto intuído de diversas maneiras e modos como sendo o mesmo, remete à noção de que os objetos intencionais são correlatos das próprias estruturas do ego transcendental. O ego vive como e enquanto sistema de horizontes intencionais a partir dos quais constitui o sentido subjetivo dos dados do seu mundo circundante.

Nessa perspectiva, Husserl explica que cada estado de consciência possui "um 'horizonte' que varia conforme a modificação de suas conexões com outros estados e com as próprias fases de seu decorrer. É um horizonte intencional, cuja característica é remeter a potencialidades da consciência que pertencem a esse mesmo horizonte" (2001, p. 62). Assim, pode-se interrogar cada horizonte a respeito do que está implicado nele, explicá-lo e revelar as potencialidades eventuais da vida psíquica. Nesse esquema, o horizonte intencional é constituído de indeterminações passíveis de determinações a partir de uma sequência de preenchimentos das intuições vazias, sendo que esse horizonte está condicionado, ou melhor, direcionado, e de certa forma antecipado enquanto possibilidade numa intuição anterior preenchida.

Nesse emaranhado de processos, o sujeito constitui o seu mundo circundante como 
mundo vivido, como mundo para um eu que o intui e lhe atribui sentido, sintetizado na sua subjetividade. Sob o prisma fenomenológico, o eu que conhece e vive, é condição de possibilidade para a percepção desses modos de apresentação do mesmo eu. A vida do eu se constitui como vivência intencional de seu fluxo de apreensões do mundo e de si mesmo.

Uma segunda espécie de polarização apresenta-se a nós agora, uma outra espécie de síntese, que abrange as multiplicidades particulares das cogitaciones, todas juntas e de maneira especial, a saber, como cogitaciones do eu idêntico, que, ativo ou passivo, vive em todos os estados vividos da consciência e que, por intermédio dele, se liga a todos os pólos-objetos (HUSSERL, 2001, p. 82).

Portanto, no fluxo das atividades da consciência o ego se constitui como polo determinado de identidade e se apresenta como orientador dessas atividades, e do qual elas obtêm seu sentido. Contudo, o ego transcendental não se apresenta a si mesmo destituído de seus estados vividos. Se assim fosse, seria meramente possibilidade de ser, absolutamente puro, mas do qual não se poderia enunciar predicações. $\mathrm{O}$ ego transcendental está dado na sua 'manifestação' enquanto eu substrato de suas atividades cognitivas transformadas num habitus ${ }^{2}$.

Husserl entende que, quando o eu realiza uma ação, determina uma predicação ou simplesmente um ato volitivo, é a ele mesmo que está constituindo e apresentando. Isso significa que o eu transcendental é pura possibilidade, mas não meramente possibilidade vazia (HUSSERL, 2006). Toda e qualquer vivência se torna parte integrante do ego, não somente enquanto fato que dura cronologicamente, mas como vivência assimilada e resguardada na sua existência consciente e histórica. Em certa medida, embora seja anterior, o ego é também o que ele vive, ou melhor, ele se desdobra em suas vivências.

No percurso das investigações fenomenológicas, compreende-se que a identidade do eu tem certo dinamismo. Todas as experiências da subjetividade têm seu início e convergem para um polo único e determinado, o ego transcendental. Nesse ínterim, enquanto substrato de suas vivências o eu se constitui também como eu humano, como pessoa, como cidadão. Husserl diz que "constituindo a si mesmo, como substrato idêntico de suas propriedades permanentes, o eu se constitui, posteriormente, como um eu-pessoa permanente, no sentido mais amplo desse termo, que nos autoriza a falar de "personalidades' inferiores ao homem" (2001, p. 83). O eu reduzido ao ego puro é o polo de identificação dos vividos enquanto subjetividade pura $^{3}$ e também se auto constitui como substância concreta, enquanto substrato de seus hábitos ${ }^{4}$. Nesse sentido, para que o ego transcendental possa ser tomado como guia transcendental da fenomenologia, precisa ser tomado na sua realidade concreta - como substrato de seus hábitos - que Husserl chamou de mônada ${ }^{5}$ (HUSSERL, 2001).

O eu completo, a "concreção do ego", como diz Husserl, é: eu como pólo idêntico mais meus habitus, mais meu mundo. Este é o sentido da noção de mônada, tomada do dinamismo leibniziano. Ela marca o triunfo total da interioridade sobre a exterioridade, do transcendental sobre o transcendente. No limite, fazer a fenomenologia do ego é fazer a própria fenomenologia (RICOEUR, 2009, p. 206).

No ego, como mônada, reside a generalidade egológica na qual se evidencia a essência imediata do ego, ou seja, seu nível máximo de generalidade e pureza. Reduzir o ego à mônada significa tomá-lo numa perspectiva de máxima generalidade eidética, nesse estado de pureza fica evidente o ponto de universalidade e identificação de todos os egos. Todos os egos possíveis são eideticamente mônadas, nesse sentido eles deixam de ser compreendidos tão somente como puras possibilidades, pois, enquanto mônadas, são concretos. Tem-se, aqui, o ápice da mudança de perspectiva da fenomenologia sobre o eu e se torna evidente o resíduo do sistema redutivo na própria arquitetura transcendental. Segundo Pelizzoli:

A mônada será a unidade entre o Ego da redução (residual, puro) e o Eu pólo idêntico dos habitus. O Eu monádico é o eu pelo qual, através da conexão de sua potência de redução - eu evidente em seus habitus e alterações - com seu "modus" ou maneira de 
existir constituindo um mundo, efetiva-se um campo originário que determina o campo da experiência. É o domínio mesmo no qual o "em-si" dos objetos aparece como "para-mim", onde as realidades podem me pertencer permanentemente (a título de habitus). Há, por conseguinte, um privilégio total do eu indubitável (mônada) (1994, p. 27).

14 Seguindo esse raciocínio, a fenomenologia desvela a estrutura eidética do ego transcendental manifestada em todos os seus sentidos. Através da variedade de modos de ser do sujeito e das variações intencionais da proposição "isso é para mim enquanto eu mesmo", chega-se à universalidade das estruturas eidéticas, princípio e fundamento de toda e qualquer atividade egóica. O ego transcendental é sempre um ego possível que compõe seus vividos a partir de sua subjetividade transcendental, na medida em que esses encontram sua razão e sentido de ser no próprio ego. $\mathrm{O}$ eu possível fundamenta o eu real, e da mesma forma, a consciência transcendental é condição de possibilidade para a consciência psicológica.

Ora, sendo o ego transcendental destituído de qualquer conteúdo real, resta voltar a análise para as estruturas do ego em geral, ou seja, àquele aspecto fundamental comum a todos os egos que lhes permite a constituição do real. De fato, é nessa generalidade que se pode encontrar uma predicação possível da essência do ego que por sua vez dá sustentabilidade às investigações fenomenológicas.

A essência é o sentido: "eu-mesmo" resistindo às variações circunstanciais da minha experiência de fato. Ela não exige referencia alguma a um par ou a uma comunidade. Neste sentido a eidética, por não recorrer a similitude da primeira e da segunda pessoas, faz a suas variações no plano solipsista. Não é fácil de pensá-lo até o fím. $\mathrm{O}$ curso da reflexão husserliana, todavia, o exige (RICOEUR, 2009, p. 208).

Porém, não se trata de uma noção psicológica, ou mesmo de uma psicologia descritiva eidética. O que está em jogo não são as essências dos fatos, seu sentido objetivo, e os mecanismos que a consciência utiliza para compô-los. O que se coloca em questão é a própria generalidade egológica que faz com que todos os sentidos do ego sejam reduzidos a uma estrutura universal da qual é possível ratificar todo o conhecimento possível e a própria identidade do eu enquanto 'ser-no-mundo'.

A partir do que foi exposto, emerge no campo das descrições fenomenológicas a noção de que é o tempo fenomenológico, que permite intuir a anterioridade do ego transcendental e que se coloca como forma universal de toda a corrente de consciência. Assim, surge a indagação pelos princípios da constituição dos conteúdos dessa corrente de consciência, o que leva a investigação aos princípios da constituição da matéria dos vividos, ou seja, a gênese constitutiva universal, já que "somente extraindo as formas das leis genéticas que lhe são inerentes podemos perceber as possibilidades de uma fenomenologia absolutamente universal" (HUSSERL, 2001, p. 93). Husserl divide a gênese constitutiva universal, a origem da formação dos conteúdos ingredientes da consciência dos vividos, em dois princípios: gênese ativa e gênese passiva.

A princípio, num primeiro olhar fenomenológico as atividades do ego revelam a gênese ativa. Husserl explica que neste caso o eu desenvolve sua atividade criadora a partir de atos próprios, utilizando-se de objetos imanentes já dados. Trata-se de um processo sintético no qual um conteúdo qualquer, de acordo com uma nova e específica motivação do eu, sofre novos processo sintéticos a partir dos quais novos objetos e compreensões são constituídos, mesmo que dentro dessa nova constituição o conteúdo do objeto primeiro esteja como que diluído dentro do novo produto da síntese. Nesse prisma, a gênese ativa representa a capacidade de dinamismo e de reformulação intuitiva da mônada.

Contudo, o ego não constitui seus fluxos intencionais e juízos a partir do 'nada', mas sim a partir de um conteúdo dado e elaborado em suas associações perceptivas. Por um lado, a gênese ativa é a atividade da consciência pela qual o eu, através de suas ferramentas, toma o conteúdo como próprio, reproduzindo-se a si mesmo na sua própria atividade. Por outro lado, a gênese passiva é a capacidade de ter conteúdos disponíveis pelos quais as atividades da gênese ativa são possíveis. Em suma, os conteúdos dados ao 
processo da gênese ativa são constituídos pela gênese passiva.

Husserl explica que em toda atividade da consciência "pressupõe sempre uma passividade, que recebe o objeto e o encontra como algo pronto de antemão; ao analisá-lo, vemo-nos diante da constituição por meio da gênese passiva" (2001, p. 94). É este aspecto da consciência, pertencente ao nível puro do ego, que permite ao eu tomar os objetos do mundo como eles mesmos, ou como Husserl sempre diz 'em carne e osso'. Além disso, segundo Husserl, "o princípio universal da gênese passiva que constitui todos os objetos que a atividade encontra intitula-se associação" (2001, p. 96). O termo associação no sentido fenomenológico não pode ser confundido com seu sentido psicológico. Nessa perspectiva, a fenomenologia é um conjunto extenso de leis essenciais da intencionalidade que presidem a constituição concreta do ego puro, ou seja, designa uma região de a priori, 'inata', sem a qual o ego como tal seria impossível.

Por conseguinte, para cada tipo de gênese há, na esfera do ego concreto, um tipo básico de síntese constitutiva. A síntese passiva é possibilidade de dispor de conteúdos mediante a unificação das atividades intencionais em um objeto polo dessas atividades; e a síntese ativa elabora e predica os conteúdos da síntese passiva e abre novas perspectivas e reformulações intencionais. Ambas se constituem na consciência intencional e são como que governadas pela constituição transcendental do tempo que lhes credita o caráter de unidade e continuidade.

Nesse viés, fica claro que é devido ao ego, enquanto mônada, através das atividades da consciência empírica ou fenomenológica, que os vividos obtêm significação e validade ${ }^{6}$. Logo, para Husserl, "qualquer prova e qualquer justificação da verdade e do ser complementam-se inteiramente em mim, e o resultado é um caráter do cogitatum do meu cogito" (2001, p. 98). Assim, o que é, é enquanto vale para algum cogito como cogitatum de um ego concreto.

Por fim, tem-se que o ego concreto constitui-se temporalmente e que a partir de suas propriedades imanentes tem a capacidade de descrever as essências e a si mesmo enquanto ego puro. Assim, a vida do ego como mônada ocorre mediante um processo infinito de atividades sintéticas e associativas temporalmente determinadas, das quais o ego transcendental é possibilidade e sua constituição concreta é a evidência. Conclui-se, portanto, que o ego fenomenologicamente reduzido é o "único domínio onde se pode encontrar sentido para as coisas, domínio dos atos de consciência doadores de sentido" (PELIZZOLI, 1994, p 32).

\section{A FENOMENOLOGIA TRANSCENDENTAL: GÊNESE DA INTUIÇÃO DO OUTRO E DAS COMUNIDADES DE MÔNADAS}

A fenomenologia transcendental, após apresentar o ego transcendental como fundamento absoluto de toda a constituição dos conteúdos e do sentido do mundo vivido, se depara com outro problema central: a possibilidade da constituição rigorosa da transcendência. Nesse sentido, Ricoeur indaga que "se a fenomenologia é a "elucidação de mim mesmo'- egologia - como é que um outro poderia jamais justificar a sua alteridade? Como, em consequência, poderá se constituir a objetividade verdadeira de um mundo comum a nós todos?" (2009, p. 214).

Em nível transcendental, o sujeito dispõe de percepções absolutamente imediatas o que lhe revela evidências apodíticas. Mas, sendo aquele que medita também um sujeito mundano, como essas evidências podem adquirir objetividade e manterem seu rigor, já que toda objetividade se dá de forma mediata? Será o ego transcendental fenomenológico um 'solus ipse'? Husserl explica que "ai está (com exceção da exclusão da existência do mundo, que talvez não seja assim tão sem importância) o problema cartesiano que deveria solucionar a veracidade divina" (2001, p. 98).

Tanto para rebater a acusação de solipsismo quanto para garantir a validade objetiva dos conteúdos da subjetividade transcendental, Husserl compõe a tese da intersubjetividade transcendental. Agora cabe compreender que tipo de intencionalidade possibilita a 
composição dos objetos da transcendência e como ela mesma evidencia o outro humano ${ }^{7}$.

A princípio, o olhar fenomenológico tem diante de si que "os outros mostram-se como regendo psiquicamente os corpos fisiológicos que lhes pertencem" (HUSSERL, 2001). Com isso, faz-se necessário uma nova perspectiva do sistema redutivo através da qual se possa suspender os aspectos mundanos do outro e trazer à evidência apodítica sua essência fenomenológica. Isso ocorre porque a manifestação do outro, prende a atenção do eu de uma forma particular, diferente da atenção dispensada aos demais componentes do seu horizonte de observação. Tal atenção se deve mediante a similariedade entre o eu e o outro. Assim, surge uma nova redução fenomenológica que Husserl chamou de epoché abstrativa.

$\mathrm{Na}$ atitude natural, numa primeira intuição, o outro se apresenta como um estranho ao eu. Trata-se de outro ser corpóreo e espiritual que 'está ai' como um diferente separado do eu. Além do mais esse outro se diferencia pela forma como se manifesta e compreende o mundo. Porém, se identifica com o eu enquanto seres psicofísicos dotados de capacidades cognitivas.

A relação eu-outro nasce como problema filosófico. Deste modo, constituir o outro como outro, em e por mim mesmo, é mostrar como o sentido "eu", nascido com a tomada de consciência da minha existência como foco de todo sentido, se comunica a esses outros e me permite dizer que esses outros lá fora são também "eus". Mas o serão somente em um sentido derivado, segundo, porque o sentido eu se constitui primeiramente em mim e para mim (RICOEUR, 2009, p. 221).

Ao suspender a vida natural e cotidiana do outro, o ego o constitui como objeto fenomenológico ${ }^{8}$. Por conseguinte, abre-se uma nova via de vinculação entre o sujeito monádico e o outro reduzido. De acordo com esses princípios, surge uma identificação analógica de verossimilhança entre aos aspectos evidentes do eu e os que o outro revela. Nesse processo, o ego monádico volta o seu olhar fenomenológico para um estranho, um fora de dele, mas análogo a ele mesmo.

Com essa camada atingimos o limite extremo a que pode nos conduzir a redução fenomenológica. Evidentemente, é preciso possuir a experiência dessa "esfera de vinculação" própria do eu para poder constituir a idéia da experiência de um outro que não eu; e sem ter essa última idéia não posso ter a experiência de um "mundo objetivo". Mas não tenho necessidade da experiência do mundo objetivo nem da experiência do outro para ter a da minha própria "esfera de vinculação" (HUSSERL, 2001, p. 110).

Entende-se por vinculação a forma específica da intencionalidade, na qual a consciência estabelece uma relação com um objeto estranho motivada pela sua apresentação. No caso do outro por sua verossimilhança em relação ao eu. A forma primeira de vinculação é a da apreensão do corpo do eu e do outro9 ${ }^{9}$. Ora, a mônada possuiu um corpo que, por sua vez, é a via de acesso à transcendência mais imediata e evidente cuja existência não pode ser suspensa. Nessa concepção, o ego como mônada, seu eu psicofísico, sua alma e todos os outros sentidos do eu permanecem unidos, coexistem numa unidade ontológica e natural enquanto corpo (HUSSERL, 2001).

Mediante essas prerrogativas, na vinculação com o outro, o eu o toma, primeiramente, como um análogo, pois se percebe a si mesmo no outro, ambos como seres racionais donos de corpos empíricos. Ricoeur afirma que na percepção do outro por analogia "se equilibram as duas exigências da fenomenologia: o respeito à alteridade do outro e o enraizamento dessa experiência de transcendência na experiência primordial" (2009, p. 227), a do ego reduzido. Num fluxo intuitivo, reduzido à relação intersubjetiva, o eu concebe o outro como um 'outro-eu-sujeito' que, embora constituído a partir do eu e lhe pertencendo, enquanto objeto intencional, vive de forma independente. Nisso, compreendese que o 'ego sum', o existir, impõe ao ego não somente a sua existência, mas a existência do outro e seu mundo vivido. Nesse ínterim, a evidência da transcendência do outro ratifica ao eu a existência de um mundo transcendente, reduzido ao campo do que lhe pertence intuitivamente. 
A experiência reduzida à esfera da vinculação possibilita ao eu a experiência do estranho a ele, de um mundo objetivo e de outros 'eus'. Assim, na subjetividade transcendental está a constituição de um mundo primordial como uma espécie de 'transcendência imanente', na medida em que esse estranho (mesmo estando aquém do eu) se constitui através das atualidades e possibilidades dos constitutivos puros do ego reduzidos às atividades de vinculação.

Para Husserl, dentro desse emaranhado de transcendências imanentes o eu se revela como ego primordial, princípio que estabelece a fenomenologia como um idealismo transcendental devido ao fato de consolidá-la como eixo da elucidação da possibilidade de correspondência epistêmica passível de explicitação entre o ego cogito e seu cogitatum. Neste ponto, tem-se a efetivação da objetividade do mundo, bem como a clareza da vida factual do ego monádico.

\begin{abstract}
Em consequência, o outro, primeiro em si (o primeiro não-eu), é o outro eu. E isso torna possível a constituição de um domínio novo e infinito do "estranho a mim", de uma natureza objetiva e de um mundo objetivo em geral, ao qual pertencem os outros e eu mesmo. Ele está na essência dessa constituição que se ergue a partir dos outros eus puros (...), de modo que aqueles que são "outros para mim" não fiquem isolados, mas que, ao contrário, se constituam, na esfera que me pertence (bem entendido), uma comunidade de eus que existem uns com os outros e uns para os outros, e que engloba a mim mesmo (HUSSERL, 2001, p. 121).
\end{abstract}

Os estudos presentes evocam que o avanço da epoché abstrativa coloca a vinculação no campo transcendental. Dessa forma, a relação de vinculação se constitui como pilar da intersubjetividade transcendental, pois ao colocar em relação o eu e o outro, em possibilidade de experiência, reduz-se por analogia o outro à identidade com o eu e, a partir dessa relação de identificação, se formam as chamadas comunidades monádicas. O mundo não será mais tomado como uma constituição particular de um ego, mas colocar-se-á em evidência a possibilidade da identificação dos "vários mundos particulares", constituídos por vários "eus". Isso significa que embora cada eu constitua seu mundo vivido próprio, há um ponto de intersecção entre todos os "eus" que é o fundamento da objetividade de um mundo comum. Nesse sentido, Dartigues, afirma que o mundo é tomado como "um fenômeno intersubjetivo, o que conduzirá Husserl a ampliar a subjetividade transcendental àquilo que denomina uma intersubjetividade transcendental. O mundo não é minha representação, ele é nosso mundo ou, enquanto mediatiza os intercâmbios entre os sujeitos, um intermundo, como designará Merleau-Ponty” (2007, p.58).

Seguindo esses princípios, para Husserl, “esse caráter de 'em carne e osso' não nos impede de concordar, sem dificuldades, que este não é o outro eu que nos é mostrado no original, não sua vida, seus próprios fenômenos, nada do que me pertence ao ser próprio" (2001, p. 122-123). Isso significa que a experiência do outro sempre será uma experiência mediata a partir do que o outro me apresenta, é o outro em carne e osso, mas revelado em perfis, idêntico ao eu, enquanto estruturas puras e em questão de ser, mas sempre apresentado distintamente, com seus modos próprios e fenômenos particulares. Caso fosse possível uma experiência absolutamente imediata do outro, ele seria absolutamente eu mesmo o que configuraria o solipsismo.

Com isso, através da noção de comunidade monádica, a fenomenologia mostra que embora o outro seja intuído a partir do eu, ele se distingue pelo fato de sua posição na esfera do mundo primordial ser pessoal e subjetiva. Sua individuação deve-se ao fato de que embora, enquanto egos transcendentais, os 'eus' se identifiquem, se distinguem na medida em que constituem sua esfera de percepções de forma própria e singular; cada um preenche seus horizontes intencionais de acordo com o 'ângulo' que ocupa no mundo e suas motivações próprias; e constitui seu substrato habitual devido às experiências próprias efetuadas em condições particulares. O outro é sempre apresentação que o eu intui e organiza dentro de seu mundo vivido; é sempre um 'ali' para um 'aqui' que o intenciona, sendo que o fato de estar ali lhe confere um campo perceptivo que, embora sendo o mesmo macro campo do 'aqui', lhe confere possibilidades específicas e distintas de apreensões. 
Constata-se, nesse ponto, uma modificação na atividade intencional. $\mathrm{O}$ eu, a partir de si mesmo, tem consciência de um ego estranho num novo tipo de representações, em um fluxo de experiências, nas quais o outro é um 'eu' apresentado em seus aspectos concretos, enquanto ele mesmo. $\mathrm{O}$ outro não é reduzido a um duplo do eu, mas se apresenta como realidade transcendente passível de identificação transcendental e dessa forma como 18 experiência primeira da condição de possibilidade da evidência objetividade ${ }^{10}$. Ricoeur ajuda a compreender esse assunto.

A originalidade de Husserl, a meu ver, reside nesta progressão metódica do solipsismo até a comunidade. Enquanto o sociólogo parte do grupo como de um fato, Husserl funda a possibilidade do laço humano sobre uma primeira camada de processos criadores de comunidade, a saber, a comunidade intencional cujo correlato é a natureza objetiva. Por seu turno, essa comunidade intencional procede do corpo a corpo que denominamos "equiparação", o qual representa a primeira transgressão da esfera do próprio (2009, p. 242).

Nesse âmbito, Husserl elenca dois níveis de comunidades monádicas: o primeiro nível se apresenta como forma objetiva da natureza intersubjetiva e o segundo nível efetiva os graus superiores do caráter intermonádico.

No primeiro nível de comunidades monádicas, o eu tem diante de si não uma mera apresentação do outro, senão a sua existência factual com todos os aspectos que ela implica. Dessa forma, estão ligadas por um campo objetivo várias consciências que se intencionam de ângulos opostos sendo que para cada uma ela mesma é o polo primordial das percepções. Há uma ambivalência dentro da própria constituição do eu: no mundo factual o eu é ego para si e alter ego para o outro simultaneamente.

Por conseguinte, forma-se a comunidade quando se expande a vinculação para outras regiões, ou seja, para outros sujeitos gerando uma cadeia de vinculações aberta a novos horizontes de assimilação ${ }^{11}$. As experiências das mônadas são como que constituídas sob nexos representativos da mesma região natural, embora de ângulos particulares. Dessa forma, as mônadas e suas representações são como que emparelhadas num complexo de interligações de horizontes intencionais (HUSSERL, 2001).

Para Husserl é nesse fluxo de representações conectadas por uma esfera de vinculação que as mônadas têm a evidência que tratam sobre o mesmo mundo. Dessa maneira, percebe-se o mundo natural em comum, mas com mundos vividos constituídos de formas diferentes. Ora, o mundo objetivo existe para o 'nós' enquanto um sistema complexo de intuições concordantes entre os $\operatorname{egos}^{12}$.

Dessa forma, fica definitiva e primitivamente fundada a coexistência do meu eu (e do meu ego concreto, em geral) com o eu do outro, da minha vida intencional e da dele, das minhas realidades e das dele; em suma, é a criação de uma forma temporal comum, e qualquer tempo primordial adquire espontaneamente a significação de um modo particular da aparição original e subjetiva do tempo objetivo (HUSSERL, 2001, p. 141).

No segundo nível da comunidade das mônadas, efetivam-se os graus superiores do caráter intermonádico. Neste ponto, não se pode limitar as investigações ao caráter psicológico da existência do outro eu, enquanto homem, como ser psicofísico dotado de alma intelectiva, que nesse sentido é como que a objetivação da mônada. Aqui, o que está em questão é a intersubjetividade no nível transcendental, cuja anterioridade em relação à psicológica se evidencia numa epoché abstrativa nos mesmos moldes da epoché transcendental do ego.

Para Husserl, o ego e os outros-egos constituem um mundo primordial próprio, o mundo da corrente da consciência, e um mundo secundário, o mundo da corrente da consciência objetivada. Segundos as descrições fenomenológicas husserlianas, o mundo primordial se constitui a partir de atos e experiências próprias do ego para si mesmo. Já o mundo secundário se constitui a partir de atos e experiências orientadas, ou seja, determinadas pelo mundo primordial de cada ego particular.

Portanto, o primeiro nível de comunidades monádicas, reduz-se o outro ao idêntico, 
por isso cabe, no segundo nível de comunidades monádicas elucidar a possibilidade da diferença no nível transcendental. Em ambos os mundos, a constituição tem sua gênese na subjetividade do ego. Contudo, resta saber como um eu pode penetrar no mundo do outro eu e a partir disso constituírem um sentido objetivo para a identidade desses mundos.

Para Husserl, tal relação entre o eu e os outros 'eus' é possível por uma atividade intencional especifica que permite a apreensão própria do sentido composto pelos sujeitos da relação. E justamente na atualização dessa possibilidade que os sujeitos podem constituir a cultura e todas as outras formas de integração associativas. Esses atos partem da subjetividade transcendental do eu em relação aos outros, da mesma forma surgem atos que fazem o movimento contrário. Neste ponto, da mesma forma que o corpo é um fator primordial para a relação abstrativa entre o eu e o outro, a psique é um fator primordial para a relação da constituição de um mundo comum. Nesse sentido, Ricoeur afirma que:

É necessário introduzir a ideia de uma "constituição psíquica do mundo objetivo", para que se realize, no sentido forte do termo "realizar, a equalização objetivante" que é a condição de todos os graus superiores de partilha comum. Assim, portanto, não só como carne, mas como psychè, deve o eu aparecer no mundo. É neste nível que os outros são também realizados como psiquismos equalizados e, desta perspectiva, separados e recíprocos (2009, p. 244).

Aqui, há um elo de comunhão de sentido entre as mônadas que se revela como princípio de toda a sociabilidade e que fundamenta a constituição de um mundo de sentido objetivo. Mundo objetivo, aqui, não significa propriamente o mundo natural, mas o mundo constituído como comum, a partir das relações intermonádicas, ou seja, das relações intersubjetivas de egos que se reconhecem como sujeitos e reconhecem o outro como outros-sujeitos. Dessa maneira, "o ego transcendental que tem a experiência do mundo em si confirma-a pelo outro, e em 'progressões constantes' verifica sua constituição objetiva; fato que, como aponta Husserl, não implica que ele precise da experiência do outro e do mundo para ter a da sua esfera própria" (PELIZZOLI, 1994, p. 39). Nota-se, aqui, que o outro não é condição de possibilidade das experiências do eu, mas sim da objetivação do conteúdo dessa experiência. A partir dessas análises nasce toda e qualquer possibilidade teórica a respeito do eu e do outro, num viés transcendental, inserido numa comunidade humana.

A constituição dessa comunidade humana permite aos sujeitos a valoração comum, embora passível de divergências, das predicações possíveis dentro da esfera de seu mundo percebido. Nesse aspecto, encontra-se o nexo da composição intersubjetiva das relações dos vividos do ego, ao que Husserl diz que "a progressão sistemática da explicitação fenomenológica transcendental do ego apodíctico chegou a descobrir o sentido transcendental do mundo em toda a sua plenitude concreta, na qual ele é o mundo de nossa vida para todos" (2001, p. 149).

Assim, a fenomenologia transcendental não é uma teoria solipsista. Ao contrário, na teoria de Husserl está presente uma proposta filosófica de abertura para uma apreensão radical do outro, na qual se prevê a constituição de um mundo objetivo comum de sentido. Seguindo esse raciocínio, toma-se a sistematização efetiva da fenomenologia como um saber radical que revela as estruturas próprias do ego, em toda a sua abrangência, numa evidência apodítica.

\section{CONSIDERAÇÕES FINAIS}

$\mathrm{Na}$ fenomenologia de Husserl, o sistema redutivo revela que é nas estruturas gerais egóicas que toda a realidade e verdade são sintetizadas e recebem o seu valor e sentido. Por isso, o ego transcendental é o resíduo último do sistema redutivo fenomenológico, sendo que, suas bases intencionais são a apercepção de si mesmo e de suas estruturas transcendentais, e as vinculações intersubjetivas puras, tudo sistematizado e evidenciado na sua vida concreta. Isso demonstra que a fenomenologia não é um idealismo vazio de 
sentido, mas a via segura para se trazer à clareza filosófica todo o complexo sistema cognitivo não revelado na visão natural e que não está muito evidente na visão psicológica.

Husserl não desmerece a capacidade das demais ciências, porém critica as tendências que tratam o sujeito e seu mundo vivido de forma fragmentada e "ensimesmada". Nesses termos, o olhar fenomenológico sobre a comunidade monádica 20 completa o sistema redutivo. E a partir desse prisma se pode, com bases em um fundamento absoluto, erigir novas asserções, já que a fenomenologia, como sempre defendeu Husserl, é a ciência primeira, não porque a mais importante, mas por ser introdução e fundamento para todas as demais. Não é possível falar em conhecimento rigoroso sem revelar as estruturas egológicas das quais ele provém, e também não é possível falar em humanidade e cultura (e tudo o que isso implica) sem revelar as estruturas que vinculam os sujeitos.

Nesses termos, a intersubjetividade transcendental aparece como um caminho eidético pelo qual se evidencia a identidade dos egos transcendentais bem como se salvaguarda a particularidade do ponto de constituição do mundo primordial de cada sujeito. $\mathrm{Na}$ esfera da intersubjetividade transcendental a comunidade dos egos transcendentais, enquanto mônadas, constitui o mundo objetivo do qual emerge o sentido da coletividade e tudo o que dela deriva. $\mathrm{Na}$ comunidade das mônadas, se revela um mundo, um tempo e um espaço, coabitado por vários egos transcendentalmente reduzidos e vinculados. Assim, tendo o 'esqueleto transcendental', torna-se possível inserir 'carne' a ele com as demais ciências numa perspectiva de complementariedade e considerando que o espírito humano escapa a qualquer tentativa de enquadramento naturalista ou psicologista.

Por fim, ratifica-se a compreensão de que na fenomenologia de Husserl, o ego transcendental continua sendo o polo absoluto doador de sentido, ícone primordial da subjetividade transcendental. No entanto, dentro do sistema de elucidação das estruturas egóicas se desvela uma nova estrutura que revela o outro na sua perspectiva fenomenológica. Assim, embora o ego se mantenha com seu papel, todo o conhecimento rigoroso e toda objetividade somente dispõem de uma evidência qualitativa na medida em que passam pelo crivo da intersubjetividade transcendental.

\section{REFERÊNCIAS}

DARTINGUES, André. O que é a Fenomenologia? 9a ed. São Paulo: Centauro, 2007.

DEPRAZ, Natalie. Compreender Husserl. Petrópoles: Vozes, 2007.

DESCARTES, René. Meditações metafísicas. São Paulo: Abril Cultural, 1998.

FRAGATA, Júlio. A Fenomenologia de Husserl como fundamento da Filosofia. Braga: Livraria Cruz, 1959.

HUSSERL, Edmund. Conferências de Paris. Lisboa: Edições 70, 1992.

HUSSERL, Edmund. Investigações lógicas. Sexta investigação: elementos de uma elucidação fenomenológica do conhecimento. São Paulo: Nova Cultural, 1988.

HUSSERL, Edmund. La Filosofia como ciencia estricta. Buenos Aires: ALMAGESTO, 1992.

HUSSERL, Edmund. Lições para uma fenomenologia da consciência interna do tempo. Lisboa: Imprensa Nacional, 1994.

HUSSERL, Edmund. Problemas fundamentales de la Fenomenología. Madri: Alianza Editorial, 1994.

HUSSERL, Edmund. La crisis de las Ciencias Europeias y la Fenomenologia transcendental. Buenos Aires: Prometeo Libros, 2008.

HUSSERL, Edmund. A idéia da fenomenologia. Lisboa: Edições 70, 1986.

HUSSERL, Edmund. A Crise da humanidade européia e a Filosofia. Porto Alegre: EDIPUCRS, 1996.

HUSSERL, Edmund. Meditações Cartesianas: introdução à Fenomenologia. 2 ed. Porto: Rés, 2001.

HUSSERL, Edmund. Idéias para uma Fenomenologia Pura e para uma Filosofia Fenomenológica. Aparecida: Idéias e Letras, 2006. 
PIZZI, Jovino. O mundo da vida: Husserl e Habermas. Ijuí: Editora Unijuí, 2006.

PELIZZOLI, Marcelo Luiz. A relação ao outro em Husserl e Levinas. Porto Alegre: EDIPUCRS, 1994.

RICOEUR, Paul. Na Escola da Fenomenologia. Petrópolis: Vozes, 2009.

SOKOLOWSKI, Robert. Introdução à Fenomenologia. São Paulo: Loyola, 2004.

ZITKOSKI, Jaime José. O método fenomenológico de Husserl. Porto Alegre: EDIPUCRS, 1994.

LÉVINAS, Emmanuel. Descobrindo a existência com Husserl e Heidegger. Trad. Fernanda Oliveira. Lisboa: Piaget, 1999.

PELIZZOLI, Marcelo Luiz. Entre o Mesmo e o Outro. A reconstrução da subjetividade pelo sentido ético da alteridade: Husserl, Heidegger e Levinas. Porto Alegre: Tese de Doutorado em Filosofia - PUCRS, 2000.

SAN MARTÍN, Javier. La estructura del método fenomenológico. Madri: UNED, 1986.

STEIN, Ernildo. Mundo vivido: das vicissitudes e dos usos de um conceito da fenomenologia. Porto Alegre: EDIPUCRS, 2004.

\section{Notas}

1 Nas análises de Pelizzoli constata-se que "por sua aspiração ao modo sistemático e universal de tomada de consciência de si que chega a um ego puro - fundamento evidente e apodítico que abarca todo sentido e todo ser -, a fenomenologia constitui-se como "idealismo transcendental". Como deseja Husserl, idealismo espiritualista que não quer senão a explicitação do meu ego como sujeito de conhecimento possível, ciência egológica sistemática abarcando todo o sentido existencial possível para mim, como Ego (cf. MC§ 41). Este idealismo se espraia desde um fundamento eidético ou essencial" (1994, p. 29).

2 Para Pelizzoli "o eu puro é assim substrato de seus habitus, eu que constitui as suas experiências por um determinado caminho, que estrutura e possibilita o ser sujeito de suas escolhas, que dá sentido ao que lhe interessa. Eu que se descobre como constituinte de um mundo, como um eu que existe, que "é nas suas experiências atuais e potenciais (cf. MC cap. IV). Ele aparelha e coordena uma forma, uma maneira própria de ser, que vem de suas próprias condições, possibilidades ou poderes; maneira ligada à sua capacidade de reelaborar situações e recordações, de criar um universo familiar" (1994, p. 26).

3 Husserl afirma que "vejo também que a apreensão dele como vivido humano, abstraindo-se de toda tese de existência, introduz no circuito tudo aquilo que não precisa necessariamente estar nele, e que, por outro lado, nenhuma exclusão de circuito pode suprimir a forma do "cogito" e eliminar o "puro" sujeito do ato: o "estar direcionado para", o "estar ocupado com", o "posicionar-se em relação a", o "experimentar", o "sofrer de" esconde necessariamente em sua essência que cada um deles é justamente um raio "a partir do eu" ou, na direção inversa, "em direção ao eu" - e esse eu é o eu puro, ao qual a redução não pode causar dano algum" (2006, p. 182-183).

$4 \mathrm{Na}$ interpretação de Ricoeur: "em primeira aproximação, o eu é o pólo idêntico da multiplicidade dos atos, da diversidade das cogitaciones. Nesta análise haviam se detido as Ideen. Husserl admite sem discurso que o ego suscita um problema análogo ao objeto e simplesmente antitético do objeto: como objeto, é um idêntico em um diverso. [...] Mas o eu é mais do que isto, ele é também o eu dos habitus, das convicções mantidas e contraídas. Esta análise, que é nova em relação às Ideen, tem dupla função: em primeiro lugar ela confirma o caráter constituído do ego. O eu não é só pólo de referência, mas também "substrato de suas propriedades permanentes". Assim, tem um estilo, o caráter de uma pessoa" (2009, p. 205).

5 Husserl toma o termo mônada da filosofia de Leibniz. Filósofo racionalista alemão, Leibniz nasceu em Leipzig, 1646, e faleceu em Hanover, em 1676. Influenciou diretamente a matemática, física e a filosofia com suas teorias. Para Leibniz, de maneira geral, a mônada é uma substância simples realmente existente dotada de qualidades que a distingue e passível de sofrer mudanças contínuas derivadas de sua própria constituição. Para Leibniz ([s.d.] p. 162) "é nas substâncias simples e não no composto ou na máquina, 
que é necessário procurar a explicação. Também só isto é que se pode encontrar na substância simples, isto é, as percepções e as suas mudanças. É só nisto também que podem consistir todas as ações internas das substâncias simples".

6 Segundo Pelizzoli "a mônada será a unidade entre o Ego da redução (residual, puro) e o Eu pólo idêntico dos habitus. O Eu monádico é o eu pelo qual, através da conexão de sua potência de redução - eu evidente em seus habitus e alterações - com seu "modus" ou maneira de existir constituindo um mundo, efetiva-se um campo originário que determina o campo da experiência. É o domínio mesmo no qual o "em-si" dos objetos aparece como "para-mim", onde as realidades podem me pertencer permanentemente (a título de habitus). Há, por conseguinte, um privilégio total do eu indubitável (mônada) [...]”(1994, p. 27).

7 Ao tratar sobre o solipsismo na fenomenologia de Husserl, Pelizzoli diz: "[...] ocorre diante de uma teoria que se quer como ciência "absolutamente subjetiva", que tem um objeto que é independente da existência ou não do mundo (cf. MC 25). Vimos que o eu transcendental do filosófo-fenomenólogo é o objeto primeiro, necessário e absoluto [...]. Husserl aponta para isto - para este solipsismo que seria um "escalão inferior" da "prima philosophia" razoes metódicas que ocorrem por questões de compreensão e sistematização; também porque a egologia transcendental fenomenológica evocará, necessariamente, o que lhe falta enquanto constituinte do mundo e da objetividade - que depende dos outros" (1994, p. 31-32).

$8 \mathrm{Na}$ visão de Pelizzoli "o outro não deve ficar fora dos parêntesis - como o mundo - que cerram o resíduo da redução; ele é constituído no eu, pois não há como compreendê-lo e falar dele senão na esfera egológica, somente aqui ele tem valor e sentido existencial" (cf. MC 109). O seu sentido deve passar pela minha vida intencional, pela síntese constitutiva e elucidar-se num "sistema de verificações concordantes", tal como os objetos" (1994, p.34).

9 Para saber mais sobre a concepção de corporeidade e a importância do vínculo fenomenológico entre corpo e consciência consultar (HUSSERL, 1994).

10 A teoria do corpo tem um papel fundamental nestas investigações, dado que para Husserl o corpo é a via de acesso para a objetividade e principio fundamental que situa o ego num mundo de experiências possíveis. Além do mais, a própria percepção do outro se dá primeiramente na percepção do corpo do outro (Cf. HUSSERL, 2001).

11 Segundo Husserl "temos, portanto, o direito de falar aqui da percepção do outro e, em seguida, da percepção do mundo objetivo, da percepção do fato de que o outro "possa ser" a mesma coisa que eu, etc., ainda que essa percepção se desenvolva exclusivamente no interior da minha esfera de vinculações. Mas isso, não impede, precisamente, a sua intencionalidade de transcender àquilo que me é próprio e, e, consequência, não impede meu ego de constituir em si mesmo um outro e de constituí-lo como existente" (2001, p. 138).

12 Neste ponto Husserl enfatiza a possibilidade de anomalias no aparato corpóreo da mônada, como por exemplo, cegueira, surdez (Cf. HUSSERL, 2001). 